\title{
Predictors of Poor Outcome in Patients with a Spontaneous Cerebellar Hematoma
}

\author{
Erik K. St. Louis, Eelco F. M. Wijdicks, Hongzhe Li, John D. Atkinson
}

\begin{abstract}
Background and purpose: The authors studied the clinical and neuroimaging features of cerebellar hematomas to predict poor outcome using comprehensive statistical models. Methods: We retrospectively reviewed clinical and neuroimaging features in 94 patients with spontaneous cerebellar hematomas to identify predictive features for a poor neurologic outcome, defined as death or dismissal to long-term care facility. Data were analyzed using chi square and Fisher's exact test with calculation of odd's ratios together with $95 \%$ confidence intervals. Results: Clinical and neuroradiologic predictors for a poor outcome at $\mathrm{p}<0.05$ were admission systolic blood pressure $>200 \mathrm{~mm} \mathrm{Hg}$, hematoma size $>3 \mathrm{~cm}$, visible brain stem distortion, and acute hydrocephalus. Presenting findings predicting subsequent death at $\mathrm{p}<0.05$ were abnormal corneal and oculocephalic responses, Glasgow coma sum score less than 8 , motor response less than localization to pain, acute hydrocephalus and intraventricular hemorrhage. Conclusion: A tree-based analysis model using binary recursive partitioning showed that cornea reflex, hydrocephalus, doll's eyes, age, and size were the most important discriminating factors. Absent corneal reflexes on admission highly predicts poor outcome (86 percent, confidence limits 67-96 percent). When a cornea reflex is present, acute hydrocephalus predicts poor outcome but only when doll's eyes are additionally absent.
\end{abstract}

RÉSUMÉ:Prédicteurs d'un mauvais pronostic chez les patients porteurs d'un hématome cérébelleux spontané. Introduction et Objectif: Les auteurs ont étudié les caractéristiques cliniques et neuroradiologiques d'hématomes cérébelleux afin de prédire au moyen de modèles statistiques ceux qui comportent un mauvais pronostic. Méthodes: Nous avons revu de façon rétrospective les caractéristiques cliniques et neuroradiologiques de 94 patients porteurs d'hématomes cérébelleux spontanés pour identifier les signes prédictifs de séquelles neurologiques importantes définies comme le décès ou le placement dans une institution de soins prolongés. Les données ont été analysées au moyen du chi carré, de la méthode exacte de Fisher ainsi que du calcul du risque relatif et de l'intervalle de confiance (IC) à 95\%. Résultats: Les prédicteurs cliniques et neuroradiologiques d'un mauvais pronostic ( $\mathrm{p}<0.05$ ) étaient une pression systolique $>200 \mathrm{~mm} \mathrm{Hg}$ à l'admission, un hématome de plus de $3 \mathrm{~cm}$, une distorsion visible du tronc cérébral et une hydrocéphalie aiguë. Les observations au moment de l'examen initial qui prédisent un décès subséquent $(\mathrm{p}>0.05)$ étaient une réponse cornéenne et oculocéphalogyre anormales, un score de moins de 8 à l'échelle de Glasgow, un score moindre pour la réponse motrice que pour la localisation à la douleur, une hydrocéphalie aiguë et une hémorragie intraventriculaire. Conclusion: Un algorythme d'analyse utilisant un cloisonnement récursif binaire a montré que le réflexe cornéen, l'hydrocéphalie, le phénomène des yeux de poupée, l'âge et la taille de l'hématome étaient les facteurs discriminants les plus importants. Des réflexes cornéens absents à l'admission étaient un signe important d'un mauvais pronostic (86\%, intervalle de confiance 67 à 96\%). Quand le réflexe cornéen est présent, une hydrocéphalie aiguë indique un mauvais pronostic, mais seulement quand le phénomène des yeux de poupée est également absent.

Can. J. Neurol. Sci. 2000; 27: 32-36

The clinical spectrum of patients with cerebellar hemorrhage is determined above all by its size and degree of atrophy of the cerebellar hemispheres. The rigid tentorium prohibits superior expansion and the small confines of the posterior fossa leave little room for a cerebellar hemorrhage. Moderate size hematomas may be well accommodated when the peripontine and cerebellar cisterns are wide. In other patients, a sudden introduction of a hemorrhagic mass may represent a rapidly developing neurosurgical catastrophe. Clinical signs of brainstem involvement often prompt suboccipital craniectomy. Ideally, it may be helpful to develop guidelines that differentiate patients who may benefit from urgent surgical intervention from those who are in a hopeless condition. In addition, family members in the emergency department may want to be informed about probable outcome when surgical evacuation is planned.

Clinical features on admission previously correlated with a poor outcome have included systolic blood pressure greater than $200 \mathrm{~mm} \mathrm{Hg}$ as part of the Cushing response, ${ }^{1}$ gaze paresis, ${ }^{1-3}$ and decreased level of consciousness, ${ }^{2-9}$ all indications of pontine

From the Department of Neurology and Department of Neurologic Surgery, Neurological and Neurosurgical Intensive Care Unit, Saint Mary's Hospital, (EKSTL; EFMW; JDA) and Section of Biostatistics (H.L.), Mayo Clinic and Foundation, Rochester, MN,USA

RECEIVEDJULY 27, 1999. ACCEPTEDINFINALFORMNOVEMBER 30, 1999. Reprint requests to: E.F.M. Wijdicks, Department of Neurology, Mayo Clinic and Foundation, 200 First Street SW, Rochester, MN 55905 
compression. CT scan features indicative of poor prognosis are midline location ${ }^{2,10-13}$ obliterated fourth ventricle and basal cisterns ${ }^{5,10,12,14,15}$ upward herniation $5,7,16,17$ intraventricular hemorrhage, ${ }^{18}$ and hydrocephalus. ${ }^{1,9,16,18,19,20}$ The decision to remove a cerebellar hematoma is determined by deterioration ${ }^{21}$ and possibly also hematoma size (more than $3 \mathrm{~cm}$ on CT) or compression of the quadrigeminal cisterns. In occasional circumstances a ventriculostomy will suffice if obstructive hydrocephalus is the main culprit in deteriorating patients. ${ }^{22-25}$

Previous studies are less than optimal because they were performed in comparatively small number of patients, before high definition CT scanning became widely available and many studies lacked comprehensive statistical analysis. This study examined retrospectively both admission clinical and CT scan features that may predict poor outcome in a large series of patients with spontaneous cerebellar hematomas. Combining both clinical features and CT scan characteristics in a statistical model may yield more relevant information than prior studies, because it closely reflects clinical practice.

\section{Methods}

Patient Data: Spontaneous cerebellar hemorrhage was confirmed by CT scan $(n=93)$ or autopsy $(n=1)$. The medical records were retrospectively reviewed. We reviewed the medical records of all Mayo Clinic Patients with intracerebral hemorrhage from 1975-1993 $(n=2,783)$. We excluded 102 patients with cerebellar hematomas due to underlying causes.

The admission clinical data in 94 patients chosen for analysis were age and sex, history of hypertension, presence of anticoagulation, syncope at hemorrhage onset, systolic blood pressure, findings on neurologic exam (in particular brain stem reflexes), and admission level of consciousness as defined by Glasgow coma score. In addition, deterioration in level of consciousness or development of new brain stem signs was determined from the medical records. Patients presenting in coma (GCS < 8) were considered deteriorated.

All CT scan reports were interpreted by staff neuroradiologists, reviewed and entered into a data form. CT scan
Table 1: Base-line characteristics of 94 patients with cerebellar hematoma

\begin{tabular}{|c|c|c|c|}
\hline \multirow[b]{2}{*}{ Variable } & \multicolumn{2}{|c|}{ Total Patients with Finding: } & \multirow{2}{*}{$\begin{array}{l}\text { Data Not } \\
\text { Available }\end{array}$} \\
\hline & Present $(\%)$ & Absent $(\%)$ & \\
\hline \multicolumn{4}{|l|}{ Medical History } \\
\hline Age $>70$ & $59(63)$ & $35(37)$ & \\
\hline Male Sex & $44(47)$ & $50(53)$ & \\
\hline \multicolumn{4}{|l|}{ History of } \\
\hline Hypertension & $74(79)$ & $20(21)$ & \\
\hline Syncope at Onset & $7(7)$ & $87(93)$ & \\
\hline Anticoagulation & $23(25)$ & $71(75)$ & \\
\hline \multicolumn{4}{|l|}{ Clinical Features } \\
\hline GCS $<8$ & $19(20)$ & $72(77)$ & $3(3)$ \\
\hline \multicolumn{4}{|l|}{ Motor Response less } \\
\hline than Localization & $16(17)$ & $77(82)$ & $1(1)$ \\
\hline Anisocoria & $13(14)$ & $78(83)$ & $3(3)$ \\
\hline Pinpoint Pupils & $10(11)$ & $81(86)$ & $3(3)$ \\
\hline \multicolumn{4}{|l|}{ Abnormal Cornea } \\
\hline Reflex & $25(26)$ & $45(48)$ & $24(26)$ \\
\hline \multicolumn{4}{|c|}{ Abnormal Oculocephalic } \\
\hline Reflex & $41(44)$ & $48(51)$ & $5(5)$ \\
\hline Skew Deviation & $6(7)$ & $85(90)$ & $3(3)$ \\
\hline Facial Palsy & $16(17)$ & $75(80)$ & $3(3)$ \\
\hline Episodic Bradycardia & $16(17)$ & $76(81)$ & $2(2)$ \\
\hline \multicolumn{4}{|l|}{ Systolic Blood } \\
\hline Pressure $>200$ & $49(52)$ & $43(46)$ & $2(2)$ \\
\hline
\end{tabular}

films available for review $(n=50)$ were graded by the authors blinded to the clinical data for anatomic location of hemorrhage (hemispheric with or without extension to midline, or primarily vermis hemorrhage), diameter of the hemorrhage in axial cross section in centimeters converted to true measurements, distortion of the fourth ventricle, brain stem distortion, presence of

Table 2: Presenting clinical and CT scan features predictive of death in 94 patients with cerebellar hemorrhage (univariate analysis)

\begin{tabular}{|c|c|c|c|c|c|c|c|}
\hline \multirow[b]{2}{*}{ Variable } & \multicolumn{2}{|c|}{$\begin{array}{l}\text { Total Patients } \\
\text { with Finding: }\end{array}$} & \multirow{2}{*}{$\begin{array}{l}\text { Data Not } \\
\text { Available }\end{array}$} & \multicolumn{2}{|c|}{$\begin{array}{l}\text { Patients Who Died } \\
\text { with Finding: }\end{array}$} & \multirow{2}{*}{$\begin{array}{l}\text { Odds Ratio } \\
(95 \% \mathrm{CI})^{*}\end{array}$} & \multirow[b]{2}{*}{ PValue** } \\
\hline & Present & Absent & & Present & Absent & & \\
\hline Abnormal CR & $25(27)$ & $45(48)$ & $24(26)$ & $20(77)$ & $6(24)$ & $26.00(7.06-95.74)$ & $\mathrm{p}=0.0001$ \\
\hline Abnormal OCR & $41(44)$ & $48(51)$ & $5(5)$ & $19(66)$ & $10(34)$ & $3.28(1.30-8.31)$ & $\mathrm{p}=0.01$ \\
\hline GCS $<8$ & $19(20)$ & $72(77)$ & $3(3)$ & $14(48)$ & $15(52)$ & $10.64(3.31-34.24)$ & $\mathrm{p}=0.0001$ \\
\hline \multicolumn{8}{|l|}{ CT Scan } \\
\hline Hydrocephalus & $47(50)$ & $38(40)$ & $9(10)$ & $22(85)$ & $4(15)$ & $7.48(2.29-24.44)$ & $\mathrm{p}=0.0009$ \\
\hline Intraventricular hemorrhage & $38(40)$ & $39(42)$ & $17(18)$ & $21(84)$ & $4(16)$ & $10.81(3.20-36.47)$ & $\mathrm{p}=0.0001$ \\
\hline
\end{tabular}

Numbers in brackets $=$ percentage of total in each column; $\mathrm{CR}=$ corneal response; $\mathrm{OCR}=$ oculocephalic response;

$\mathrm{CI}=$ confidence interval obtained from univariate logistic regression or the exact method; *Odds ratios are for death versus survival;

**Two-sided p-values were derived from the chi square test or Fisher's exact test. 
Table 3: Presenting features predictive of dependent outcome in 94 patients with cerebellar hemorrhage (univariate Analysis)

\begin{tabular}{|c|c|c|c|c|c|c|c|}
\hline \multirow[b]{2}{*}{ Variable } & \multicolumn{2}{|c|}{$\begin{array}{l}\text { Total Patients } \\
\text { with Finding: }\end{array}$} & \multirow{2}{*}{$\begin{array}{l}\text { Data Not } \\
\text { Available }\end{array}$} & \multicolumn{2}{|c|}{$\begin{array}{c}\text { Dependant Patients Who Died } \\
\text { with Finding: }\end{array}$} & \multirow{2}{*}{$\begin{array}{l}\text { Odd's Ratio } \\
(95 \% \mathrm{CI})^{*}\end{array}$} & \multirow[b]{2}{*}{ PValue** } \\
\hline & Present & Absent & & Present & Absent & & \\
\hline \multicolumn{8}{|l|}{ Admission } \\
\hline $\mathrm{SBP}>200$ & $49(52)$ & $43(46)$ & $2(2)$ & $15(63)$ & $9(37)$ & $4.09(1.38-12.09)$ & $\mathrm{p}=0.01$ \\
\hline Hydrocephalus & $47(50)$ & $38(40)$ & $9(10)$ & $14(64)$ & $8(36)$ & $4.14(1.35-12.66)$ & $\mathrm{p}=0.01$ \\
\hline Brain Stem distortion & $25(27)$ & $22(22)$ & $47(50)$ & $8(67)$ & $4(33)$ & $4.67(1.01-21.65)$ & $\mathrm{p}=0.05$ \\
\hline Size $>3 \mathrm{~cm}$ & $47(50)$ & $21(22)$ & $26(28)$ & $16(84)$ & $3(16)$ & $5.33(1.30-21.94)$ & $\mathrm{p}=0.02$ \\
\hline
\end{tabular}

Numbers in brackets = percentage of total in each column; CI = confidence interval obtained from univariate logistic regression or the exact method; $\mathrm{SBP}=$ systolic blood pressure.

*Odds ratios are for being dependent versus nondependent; **Two-sided p-values were derived from the chi square test or Fisher's exact test.

profound intraventricular hemorrhage (involvement of third and lateral ventricles), and acute hydrocephalus. Upward herniation was defined as obliteration of the ambient and quadrigeminal cisterns and change of the posterior portion of the supracerebellar cistern according to Osborn criteria. ${ }^{17}$

Outcome Measures: Outcome was determined at least three months after presentation. Poor outcome was defined as dependency (dismissal to long-term care facility) or death.

Statistical Methods: Data were analyzed using chi square test or the Fisher's exact test. Odds ratios together with $95 \%$ confidence intervals were obtained using univariate logistic regression or the exact method. Tree-based models provide an alternative to linear logistic regression models for classification problems. The models are fitted by binary recursive partitioning whereby a data set is successively split into increasingly homogenous subsets. In addition, missing covariates are inputted using available covariates. The $S$ plus $r$ part procedure was used to fit the model. ${ }^{26,27}$ For each subgroup based on the regression tree, the probability of having poor outcome and 95 percent confidence intervals was also calculated.

\section{RESULTS}

Patients Forty-four (47\%) patients were men and fifty (53\%) women, aged 27-89 years (median $=73$ years, mean $=70$ years). Seventy-four patients $(79 \%)$ had a history of hypertension. Twenty-three patients $(25 \%)$ received anticoagulation, with 16 patients $(70 \%)$ anticoagulated beyond therapeutic range (international normalized ratio more than two or prothrombin time more than 12 seconds). The most common clinical presentation alone or in combination were nausea and vomiting, headache, slurred speech, dizziness or vertigo, and imbalance or inability to walk. Neurological examination findings indicating brain stem compression included involvement of the third, fourth, fifth, sixth, and seventh cranial nerves. Dysautonomia as reflected by bradycardia or marked increase in blood pressure were common observations. The clinical data are shown in Table 1.
Thirty-one patients $(33 \%)$ were treated with suboccipital craniectomy and hematoma evacuation and sixteen patients (17\%) with ventriculostomy. Twenty-eight of 31 (90\%) patients who deteriorated later or presented with coma had surgery. Thirty-one patients (33\%) died, and twenty-six patients $(41 \%)$ of those surviving had a dependent outcome.

\section{Statistical Analysis of Poor Outcome}

The univariate analysis of clinical and neuroimaging features which were significantly predictive of death and dependent outcome are shown in Table 2 and 3. The odd's ratios measure the excess occurrence of death or dependent outcome of the patients with these features over the patients without these features. Notable findings not predictive of death or poor outcome were anticoagulation respectively for death and dependency, dysautonomia (bradycardia, hypertension), certain eye findings, ventricular distortion and any neurosurgical intervention (Table 4).

Due to missing data and many possible interaction effects of

Table 4: Factors not predictive of death or dependency in univariate analysis of 94 patients with cerebellar hemorrhage

\begin{tabular}{lll}
\hline Variable & N & P value \\
\hline Sex & 94 & 0.46 \\
History of hypertension & 94 & 0.71 \\
Anticoagulation & 94 & 0.45 \\
Pin point pupils & 91 & 0.42 \\
Skew deviation & 91 & 0.66 \\
Bobbing & 91 & 0.70 \\
Facial palsy & 91 & 0.70 \\
Dysautonomia & 92 & 0.13 \\
Craniotomy & 94 & 0.97 \\
Ventriculostomy & 94 & 0.40 \\
\hline
\end{tabular}




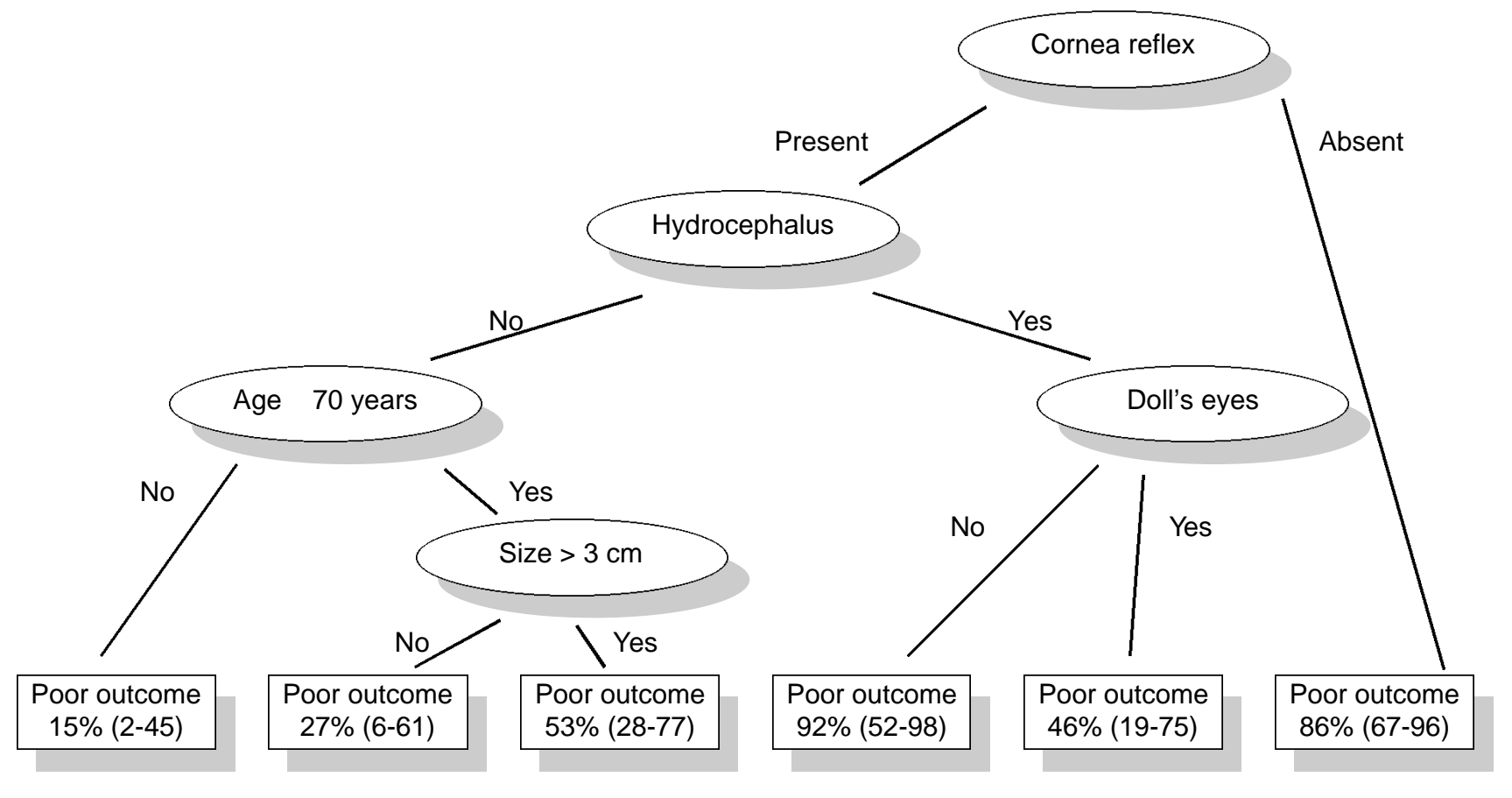

Figure: Classification and regression tree analysis of poor outcome in patients with cerebellum hematoma. The numbers are the probabilities of having poor outcome and 95 percent confidence intervals.

the clinical and neuroimaging features on poor outcome, we performed a classification and regression tree analysis. Variables used in the regression tree analysis included age $>70$, anisocoria, corneal reflexes, oculocephalic responses, GCS score more than 8 , size more than $3 \mathrm{~cm}$, hydrocephalus, motor response, of the Glasgow coma score.

The Figure shows the resultant classification and regression tree.

\section{DISCUSSION}

Acute space occupying cerebellar hemorrhages may cause major morbidity or death due to medullary compression from tonsillar herniation through the foramen magnum, midbrain compression by vermian herniation through the tentorial hiatus or from direct brain stem compression. Acute obstructive hydrocephalus may contribute due to increased intracranial pressure as a secondary phenomenon.

Several admission features predictive for a poor outcome in our series corroborate previous observations, including admission systolic blood pressure above $200 \mathrm{~mm} \mathrm{Hg},{ }^{1}$ abnormal corneal and oculocephalic reflexes, GCS less than $8^{1,2,9}$ motor response worse than localization, size greater than $3 \mathrm{~cm}, 4,8-10,18,28$ visible brain stem distortion, acute hydrocephalus, ${ }^{1,9,16,18}$ and intraventricular hemorrhage. ${ }^{10}$

We did not find age, premorbid hypertension, anisocoria, or skew deviation to be significant predictive factors for poor outcome. Anticoagulation did not significantly alter patients' clinical course, including patients anticoagulated beyond the usual therapeutic range, but this may represent our practice using early vitamin $\mathrm{K}$ or fresh frozen plasma. Surgical intervention did not significantly impact on outcome. This may be a consequence of our neurosurgical practice to preferably intervene in deteriorated patients. It is not known whether early surgery in these patients would result in a less detrimental functional outcome. In many studies, surgical intervention is determined by clinical criteria. We recently found that, at least in our referral institution, neurosurgeons prefer to evacuate small hematomas, but will operate on large hematomas in patients younger than 70 and withhold surgery from older patients. These biases may impact on outcome. ${ }^{29}$

The significant correlations with poor outcome may harbor covariates. Therefore, we further partitioned the data and extracted the most important discriminating factors. Bilateral absent cornea reflex highly predicted poor outcome, but its absence at presentation occurred in half of the patients. When cornea reflex is present, acute hydrocephalus predicts poor outcome but particularly when doll's eyes are additionally absent. These findings re-emphasize a lasting effect on the pontine structures due to enlargement of the fourth ventricle or direct compression.

Our study has limitations. First, missing CT scan films may have underestimated the importance of hemorrhage volume as a factor in prediction of a poor outcome. Also, brain stem distortion could not be accurately assessed in 50\% of the patients, and this CT feature needs further assessment in future studies on prognostication and may be better determined with MR imaging. Second, the noteworthy finding of absent cornea 
reflex was not documented in one quarter of the patients. Thus, the correlation could have been different if a larger percentage of patients were examined more thoroughly. It is questionable whether clinicians were more likely to perform the cornea reflex on the sickest patients, skewing the data further. Third, it should be noted that with every partitioning in the decision tree, the subsequent numbers are small and confidence intervals are wide. Firm recommendations are therefore not possible.

There is growing interest in the efficient utilization of intensive care resources, therefore it is important to examine whether such intervention will affect outcome and make a difference in mortality. Our large series of patients provides a more nuanced understanding of outcome in cerebellar hemorrhage and is helpful when framing prognostic estimates to family members.

In summary, we found that 86 percent (95 percent C.I. 67-96 percent) of the patients with absent cornea reflex on admission had poor outcome. Hydrocephalus on CT scan emerged as a subsequent important discriminating factor for patients with a present cornea reflex. When hydrocephalus is present and oculocephalic responses are absent, 92 percent (95 percent C.I. 52-98 percent) of the patients had poor outcome. When hydrocephalus is absent, age more than 70 years and size of the hematoma more than $3 \mathrm{~cm}$ determined poor outcome; 53 percent of these patients had poor outcome.

These data can be used to assess the initial severity of the cerebellar hemorrhage and plan for an aggressive or supportive course of management. When cornea reflex is absent, suboccipital craniectomy for clot evacuation may result in major morbidity if patients survive. A randomized clinical trial may confirm this conclusion.

\section{REFERENCES}

1. Dunne JW, Chakera T, Kermode S. Cerebellar hemorrhage diagnosis and treatment: a study of 75 consecutive cases. Quarterly Journal of Medicine 1987;64(245):739-754.

2. Ott KH, Kase CS, Ojemann RG, Mohr JP. Cerebellar hemorrhage: diagnosis and treatment. Arch Neurol 1974;31:160-167.

3. Brennan RW, Bergland RM. Acute cerebellar hemorrhage: analysis of clinical findings and outcome in 12 cases. Neurology 1977;27:527-532.

4. Kobayashia S, Sato A, et al. Treatment of hypertensive cerebellar hemorrhage - surgical or conservative management? Neurosurg 1994;34(2):246-250.

5. Waidhauser E, Hamburger C, Marguth F. Neurosurgical management of cerebellar hemorrhage. Neurosurg Rev 1990;13; 211-217.

6. Firsching R, Huber M, Frowein RA. Cerebellar hemorrhage: management and prognosis. Neurosurg Rev 1991;14:191-194.

7. Van Loon J, Van Calenbergh F, Goffin J, Plets C. Controversies in the management of spontaneous cerebellar hemorrhage: a consecutive series of 49 cases and review of the literature. Acta Neurochirurgica (Wien) 1993;122:187-193.
8. Mezzadri JJM, Otero JM, Ottino CA. Management of 50 spontaneous cerebellar hemorrhages: importance of obstructive hydrocephalus. Acta Neurochirurgica (Wien) 1993;122:39-44.

9. Melamed N, Satya-Murti SS. Cerebellar hemorrhage: a review and reappraisal of benign cases. Arch Neurol 1984;41:425-428.

10. Pozati E, Grossi C, Padovani R. Traumatic intracerebellar hematomas. Neurosurg 1982;56:691-694.

11. Turner DA, Howe JF. Cerebellar hemorrhage as evaluated by computerized tomography. West J Med 1982;136:198-202.

12. Heros RC. Cerebellar hemorrhage and infarction. Stroke 1982;13(1):106-109.

13. McKissock W, Richardson A, Walsh L. Spontaneous cerebellar hemorrhage: a study of 34 consecutive cases treated surgically. Brain 1960;83(1):1-9.

14. Weisberg LA. Acute cerebellar hemorrhage and CT evidence of tight posterior fossa. Neurology 1986;35:858-860.

15. Little JR, Tubman DE, Ethier R. Cerebellar hemorrhage in adults: diagnosis by computerized tomography. J Neurosurg 1978;48:575-579.

16. Taneda M, Hayakawa T, Mogami H. Primary cerebellar hemorrhage: quadrigeminal cistern obliteration on CT scans as a predictor of outcome. J Neurosurg 1987;67:545-552.

17. Osborn AG, Heaston DK, Wing SD. Diagnosis of ascending transtentorial herniation by cranial computed tomography. Am J Radiol 1978;130:755-760.

18. Salazar J, Vaquero J, Martinez P, et al. Clinical and CT scan assessment of benign versus fatal spontaneous cerebellar haematomas. Acta Neurochirurgica 1986;79:80-86.

19. Mathew P,Teasdale G, Bannan A, Oluoch-Olunya D. Neurosurgical management of cerebellar haematoma and infarct. JNNP 1995;59:287-292.

20. Seelig JM, Selhorst JB, Young HF, Lipper M. Ventriculostomy for hydrocephalus in cerebellar hemorrhage. Neurology 1981;31:1537-1540.

21. St. Louis EK, Wijdicks EFM, Li H. Predicting neurologic deterioration in patients with cerebellar hematomas. Neurology 1998;51:1364-1369.

22. Auer LM, Auer T, Sayama I. Indications for surgical treatment of cerebellar hemorrhage and infarction. Acta Neurochirgica 1986;79:74-79.

23. Greenberg J, Skubick D, Shenkin H. Acute hydrocephalus in cerebellar infarct and hemorrhage. Neurology 1979;29:409-413.

24. Unwin DH, Batjer HH, Greenlee RG. Management controversy: medical versus surgical therapy for spontaneous intracerebral hemorrhage. Neurosurg Clin North Am 1992;3(3):533-537.

25. Yoshida S, Sasaki M, Oka H, et al. Acute hypertensive cerebellar hemorrhage with signs of lower brain stem compression. Surg Neurol 1978;10:79-83.

26. Breiman L, Friedman JH, Olshen R, Stone CJ. Classification and regression trees, 1984, Wadsworth International Group, Belmont, California

27. Terneau TM, Atkinson EJ. An introduction to recursive partitioning using R part routines, 1997 technical report \#61, Section of Biostatistics, Mayo Clinic.

28. Zieger A, Vonofakos D, Steudel WI, Dusterbehn G. Nontraumatic intracerebellar hematomas: evaluation by computed tomography. Surg Neurol 1984;22:491-494.

29. Wijdicks EFM, St. Louis EK, Li H, Atkinson JD. Clinician's biases toward surgery in cerebellar hematomas: an analysis of decisionmaking in 94 patients. Cardiovasc Dis 2000: in press. 